
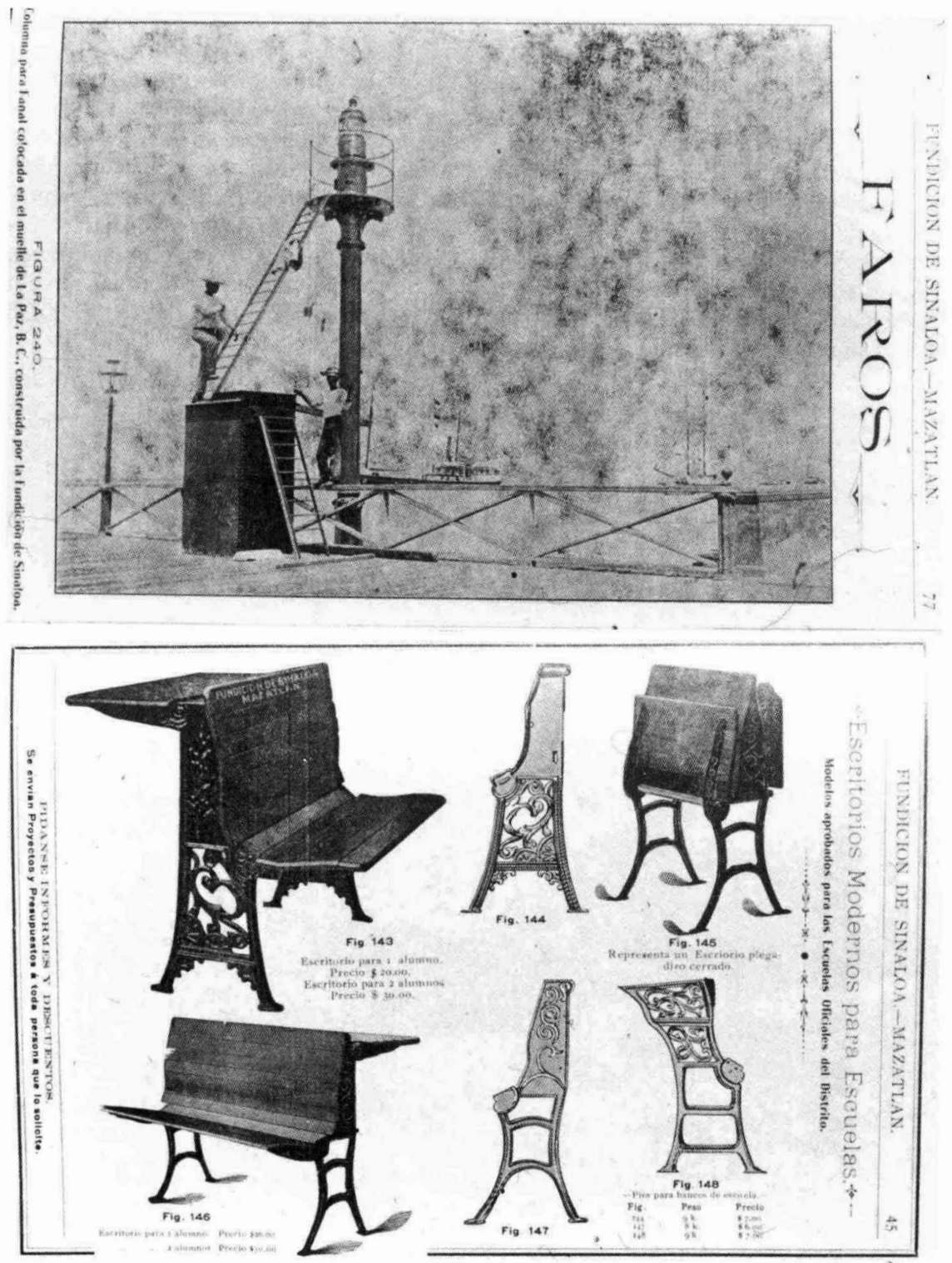


\title{
Reflexiones teóricas sobre la noción de cultura popular: un balance de 25 años de trabajo
}

\author{
Lise Andries
}

\section{L}

as nociones de cultura popular y de cultura de gran difusión tienen un significado más amplio que la de literatura popular, ya que incluyen junto a los textos impresos (almanaques, periódicos o pasquines, volantes, imágenes) las manifestaciones de la cultura oral (creencias y tradiciones orales), así como de la cultura política (panfletos, folletos), de los ritos (fiestas, religión) y de las prácticas colectivas (divertirse e instruirse, vestirse, alojarse, alimentarse). En efecto, el estudio de la cultura popular está en el cruce de diversas disciplinas: la historia cultural, la historia de la cultura material, la historia de la edición, la historia de las ideas, la historia de las instituciones (escuela, alfabetización), la historia literaria, la etnología y el folclor. Asimismo, subrayemos lo impreciso de la expresión "cultura popular" que puede designar al mismo tiempo una cultura para el pueblo, una cultura creada por éste o una cultura popularizada porque ha sido ampliamente difundida. Quisiera tratar de mostrar en este artículo el carácter eminentemente historiado de estas nociones y seguir el desarrollo cronológico de las investigaciones consagradas a ellas durante las dos últimas décadas, mostrando cómo se inscribieron en los debates intelectuales de dicho periodo. Sin embargo, este balance tiene un carác- ter forzosamente limitado, porque se refiere antes que nada a la investigación europea y se basa en mi propio tema de investigación, la literatura ambulante en Francia. Sería, por lo tanto, deseable que este estudio se extendiera a otras culturas, en particular al espacio latinoamericano.

Durante los años de 1960 a 1970, comienzan a aparecer numerosos trabajos en varias partes de Europa sobre la literatura popular escrita, difundida entre los siglos XVI y XIX. El estudio de los cuentos de la tradición oral pasa entonces a un segundo plano, primero porque ya existen en ese momento importantes obras de referencia ${ }^{1}$ y, probablemente también, porque el folclor, profusamente utilizado por los movimientos de extrema derecha y los teóricos de la superioridad racial entre las dos guerras, se ha convertido en una disciplina sospechosa en Europa. Rudolf Schenda publica una encuesta sobre la cultura popular alemana de los siglos XVIII y $\mathrm{XIX}^{2}{ }^{2} \mathrm{~J}$. Caro Baroja, un importante artículo sobre la "literatura de cordel", ${ }^{3}$ y A. Rodríguez Monino, un diccionario de los pliegos sueltos rimados que circu-

1 Thompson, Motif, 1932-1936; Aarner y Thompson, Types, 1961; Propp, Morphologie, 1965.

${ }^{2}$ Schenda, Volk, 1970.

${ }^{3}$ Baroja, "Ensayo", 1969. 
laban en la España del renacimiento. ${ }^{4} \mathrm{Pe}-$ ter Burke procede a un análisis comparado de la cultura popular en el conjunto del área europea ${ }^{5}$ y el historiador Robert Mandrou publica De la culture populaire aux XVII et XVIII siècles: la Bibliothèque blene de Troyes." (La cultura popular en los siglos XVII y XVIII: la Biblioteca Azul de Troyes) Para estos autores, la literatura popular que identifican con la cultura popular da testimonio de las creencias, las prácticas y los sueños de la gente de antaño, de esta mayoría silenciosa por la cual se interesa entonces la historia de las mentalidades. Se produce así un feliz encuentro de la historia con una literatura escrita (aunque se trate de una literatura un poco particular por ser marginal), que accede de golpe al estatus de documento para el estudio de los comportamientos. Se supone, en efecto, que la Biblioteca Azul o los pliegos sueltos en España revelan una concepción del mundo más coherente que las huellas fragmentarias dejadas en los archivos y en aquéllas más fugitivas aún de la literatura oral.

Todas estas publicaciones inauguran una larga serie de estudios sobre la cultura popular que ponen en tela de juicio el sentido y la validez de dicha expresión, y se inscriben en un contexto científico e ideológico que es necesario reconstruir. Robert Mandrou, por ejemplo, se inspira en las nuevas perspectivas teóricas de la historia de las mentalidades inaugurada por la Escuela Francesa de los Anales. Si se la compara con la historiografía clásica, que privilegiaba a las elites sociales, intelectuales y políticas, la Escuela de los

\footnotetext{
${ }^{4}$ Rodríguez, Diccionario, 1970.

${ }^{5}$ Burke, Popular, 1978.

${ }^{6}$ Mandrou, Culture, 1964.
}

Anales, ${ }^{7}$ siguiendo al historiador Lucien Febvre, opera un vuelco y cambia de perspectiva. Se aboca a dar cuenta de los grandes movimientos colectivos más que de las trayectorias individuales y pone el acento en el tiempo largo de las grandes mutaciones sociales, en detrimento de la historia de los acontecimientos. Así abre camino a una historia "vista desde debajo". Por ello, la literatura popular, destinada al gran público y vendida de manera ambulante durante casi tres siglos en Italia, España, Portugal, Alemania, Francia e Inglaterra, parece particularmente indicada para insertarse en esta nueva manera de historiar.

Las definiciones de "pueblo" y de "lo popular" deben mucho, entonces, a los trabajos de los historiadores influidos por la crítica marxista, como George Rudé y E. J. Thompson en Inglaterra ${ }^{8}$ o, en Francia, a Albert Soboul, un historiador de la revolución [de 1789]. Es también en esta época cuando se traducen en Europa las obras de historiadores soviéticos, como Boris Porchnev, sobre las revueltas campesinas, o Mikaël Bakhtine, sobre la cultura popular en el renacimiento. ${ }^{9} \mathrm{Cul}-$ tura y literatura popular adquieren su sentido en relación con nociones antitéticas como dominantes/dominados, burguesía/proletariado, ideología dominante/alienación, cultura erudita/cultura popular. Curiosamente, los historiadores que tra-

${ }^{7}$ Se dio este nombre en la década de 1960 a un grupo de historiadores franceses asociados para fundar la revista Annales, entre los cuales los más famosos son Lucien Febvre y Fernand Braudel.

${ }^{8}$ Véanse Rudé, Crowd, 1964, y Thompson, Making, 1963.

${ }^{9}$ Porchnev, Soulèvements, 1963; Bakhtine, Oeuure, 1970. 
bajan en estas perspectivas van a defender dos tesis diametralmente opuestas. Para Robert Mandrou, por ejemplo, los libros populares constituyen un instrumento de propaganda y de alienación de las masas:

Los pequeños libros de cubierta azul, almanaques, cuentos, cánticos, historias míticas, han constituido, en la realidad, un freno, un obstáculo a la toma de conciencia de las condiciones sociales y políticas a las que estaban sometidos [los] medios populares.

Y ciertamente los numerosos libros religiosos escritos por los eclesiásticos en el siglo XVII y publicados bajo cubierta azul con fines edificantes, o bien las novelas de caballería de la edad media como Les Conquêtes de Charlemagne (Las conquistas de (arlomagno), reeditadas hasta finales del siglo XIX sin que su visión del mundo feudal se haya modificado en lo fundamental, pueden acreditar esta tesis. Por el contrario, para otros historiadores, la cultura popular funciona como una cultura de resistencia en la que se expresan una protesta y comportamientos subversivos. Los trabajos de Eric Hobsbawn sobre Bandits, en 1969, y Primitive rebels, en $1974,{ }^{10}$ se inscriben en esta perspectiva. Igualmente, podemos mencionar el importante libro de Richard Hoggart, The Uses of Literacy, ${ }^{11}$ que tiene por tema las lecturas en el mundo obrero de la Inglaterra de los años cincuenta y demuestra que su lectura, lejos de producir alienación, genera un discurso distanciado en relación con los libros y un análisis inventivo, crítico o paródico. Gramsci había defendido anteriormente este punto de

${ }^{10}$ Hobsbawn, Bandits, 1969, Primitive, 1974.

"Hoggart, Uses, 1957. vista en uno de los textos de sus Cabiers de prison (Cuadernos de la cárcel), titulado Gli intellettuali e l'organizzazione della cultura. ${ }^{12}$

Esta segunda interpretación domina ampliamente la reflexión teórica en los años de 1970 a 1980 . Es el momento en que aparecen las grandes obras sobre el carnaval, la de E. Le Roy Ladurie, Le Carnaval de Romans, publicada en $1979 ;{ }^{1.3}$ la de N. Z. Davis, Les Cultures du peuple en 1980, y la del historiador italiano Carlo Ginzburg, Il formaggio e i vermi ${ }_{14}^{14}$ que cuenta cómo, a comienzos del siglo XVII, un pastor del Friul inventa una cosmogonía personal a partir de sus lecturas. Es también el momento en que Michel Foucault publica Surveiller et punir, ${ }^{15}$ libro que examina en particular el gusto creciente de la opinión pública por la "nota roja" en el transcurso del siglo XVIII y la multiplicación de las narraciones de vidas de criminales en la literatura ambulante. Con Michel Foucault pasamos de la cultura de masas a la cultura de los marginados, que asocia al pueblo con los locos, los "desviantes", los niños, las mujeres y, pronto, los pueblos colonizados. En efecto, el interés por la literatura popular no se separa de los grandes movimientos sociales occidentales de la época, que conjuntan las revueltas estudiantiles a comienzos de los años setenta, las primeras reivindicaciones feministas, la lucha contra la guerra de Vietnam y la denuncia del imperialismo.

${ }^{12}$ Existe edición en español, Gramsci, Intelectuales, 1975.

${ }^{13}$ Existe edición en español, Le Roy Carnaval, 1994. [N. del E.]

${ }^{1.4}$ Existe edición en español, Ginssburg, Formaggio, 1976.

${ }^{15}$ Existe edición en español, Foucault, Vigilar, 1984. [N. del E.] 
Por aquellos años, la cuestión de lo "popular" interesa principalmente a los historiadores; pero suscita también una reflexión de orden literario con el cuestionamiento de los modelos de "la ideología dominante" y, en particular, de la literatura clásica y canónica. $\mathrm{El}$ acento se desplaza de los grandes autores hacia las literaturas marginales. Se forjan nociones como las de "paraliteratura" e incluso de "contraliteratura", mientras aparecen nuevos objetos de estudio. La literatura popular, pero también la literatura policiaca, la fotonovela y el folletín se convierten sin restricciones en textos literarios. En 1969 se inaugura en Francia el Museo de Artes y Tradiciones Populares, una especie de consagración institucional de la investigación etnológica en el ámbito de lo popular. Los años setenta, dominados por la historia de las mentalidades y las teorías marxistas, son, por lo tanto, un periodo esencial para comprender de qué manera se construyó en Europa la noción de literatura popular.

Pero el decenio siguiente marca la entrada a la era de la duda. Historiadores, como Roger Chartier, cuestionan las certezas triunfantes del periodo precedente. La noción de cultura popular gana matices y se precisa. El pueblo ya no es considerado como una entidad abarcadora, ahora sus diversas estratificaciones (económicas y sociales, geográficas, religiosas, sexuales y generacionales) son lo que lo caracterizan. Se considera que existen prácticas culturales diferentes según los grupos de edad, para los hombres y para las mujeres, en región católica o en región protestante, en el campo o en las ciudades. Ya no parece legítimo asimilar la cultura popular a la literatura popular, como lo pensaban Peter Burke y Robert Mandrou.
Los historiadores prefieren elegir un enfoque de tipo sociológico para definir la cultura popular: la definen por el hábitat, la pertenencia a una comunidad profesional, las maneras de leer. De ahí en adelante la noción de literatura popular se extiende a los carteles, canciones, grabados, enseñas y todas las formas de impresos de amplia circulación. Los trabajos de los historiadores de los años ochenta se centran más sobre las prácticas que sobre conceptos abstractos como el de pueblo y de "lo popular". Ellos definen diferentes formas de lectura; como Rolf Engelsing, ${ }^{16}$ quien defiende la hipótesis de que la Europa antigua se caracteriza por una lectura "intensiva" de los textos (acceso a una cantidad limitada de obras, a menudo aprendidas de memoria y sacralizadas); mientras que el siglo XIX abre la etapa de la lectura "extensiva", con un repertorio de libros que se amplía y una lectura más desenvuelta y rápida. Otros investigadores centran su trabajo en las modalidades de difusión de los impresos: es el caso de Elizabeth L. Eisenstein en The Printing Press as an Agent of Change. Communications and Cultural Transformations in Early Modern Europe $^{17}$ (La letra impresa como agente del cambio. Comunicación y tranformaciones culturales en los inicios de la Europa moderna) o de J.-F. Botrel, quien estudia "Los ciegos vendedores ambulantes de impresos en España" 18 y de Diego Ramada Curto con su artículo sobre las "Literaturas de amplia circulación en Portugal". ${ }^{19}$

Todos ellos cuestionan el carácter intemporal de la cultura popular. Esta con-

\footnotetext{
${ }^{16}$ Engelsing, Sozialgeschichte, 1973.

${ }^{17}$ Eisenstein, Printing, 1979.

${ }^{18}$ Botrel, "Ciegos", 1974.

${ }^{19}$ Ramada, "Literaturas", 1996.
} 
cepción, ligada al nacimiento del folclor a finales del siglo XVIII, colocaba a la cultura popular en un tiempo mítico e inmóvil y, muy a menudo, la asimilaba a una edad de oro del campesinado, cuyos últimos vestigios era necesario recolectar piadosamente antes de que desapareciera. Por el contrario, las obras publicadas en los años ochenta muestran que la cultura popular evoluciona en el tiempo. Se pueden citar en particular los trabajos de B. Capp sobre los almanaques ingleses ${ }^{20} y$ los de Margaret Spufford sobre la manera en que las novelas de venta ambulante se dirigen a los lectores. ${ }^{21}$ Por mi parte, he intentado subrayar en mis estudios sobre la Biblioteca Azul y la literatura ambulante en Francia que no se trataba de una literatura inmóvil y que los impresores habían desarrollado estrategias para adaptarse a las corrientes de ideas, a las modas literarias y a la evolución de las expectativas de los lectores. En efecto, el catálogo de títulos se renovó con el tiempo. La literatura de "nota roja" y los cuentos de hadas aparecieron en esta colección en el siglo XVIII, las novelas que daban lugar a reediciones fueron reescritas $o$ adaptadas, a menudo, en busca de una moralización y de una mayor preocupación por el decoro.

Pero lo que sobre todo caracteriza al decenio de 1980 a 1990 es el cuestionamiento radical de la oposición entre cultura erudita y cultura popular que había ocupado el centro del debate ideológico en los años setenta. Es a finales de aquellos años cuando se derrumban la mayoría de los regímenes comunistas y las teorías políticas sobre las que estaban construidos.

${ }^{20}$ Capp, English, 1979.

${ }^{21}$ Spufford, Small, 1981.
No es sorprendente que términos como los de "pueblo" o de "lo popular", fuertemente historiados y politizados, carguen con las consecuencias de tal coyuntura. La oposición dominadores/dominados ya no está a la orden del día. Además también se rompe-¿definitivamente?-con la era de los grandes pensadores y de los grandes sistemas de ideas como el estructuralismo, el marxismo y el psicoanálisis. Ya en 1974, en un texto sobre "La belleza de lo muerto", Michel de Certeau había subrayado que el hecho mismo de hablar de cultura popular transformaba a ésta en un objeto muerto, museografiado, y que al investigar sobre ella aprendíamos "menos sobre la cultura popular que sobre lo que representa para un universitario progresista, hablar, hoy; de cultura popular".

Nuevos modos de abordar la cultura popular se dibujan entonces. Sobrepasando la vieja oposición entre literatura popular y literatura erudita, se subrayan los procesos de ósmosis, de intercambio, de contaminación recíproca entre textos destinados a públicos diferentes. Los libros de Roger Chartier, especialmente Lectures et lecteurs dans la France d'Ancien Régime, publicado en $1987,{ }^{22}$ y Culture écrite et société (Cultura escrita y sociedad), aparecido en 1996 , proceden a un cuestionamiento más radical aún sobre la noción de literatura y de cultura popular. Para Roger Chartier, hay que vincular lecturas, prácticas y comunidades precisas, y considerar que existen diferentes usos de los textos, de las lecturas escolares, edificantes, profesionales o didácticas. Es el momento en que la historia de las mentalidades, con todo lo que la funda en el plano con-

\footnotetext{
22 Existe una edición en español, Chartier, Lecturas, 1994.
} 
ceptual, pasa por un tamiz crítico. Más que hablar de mentalidades -término confuso- y de la lectura en general, los historiadores van a preferir, de ahora en adelante, referirse a un mercado fragmentado de lectores. Estas nuevas investigaciones se inscriben además en una disciplina en pleno desarrollo, la historia del libro y de la lectura. L'Histoire de l'édition française (Historia de la edición francesa), dirigida por Roger Chartier y Henri-Jean Martin, cuyos volúmenes aparecen de 1982 a 1986, marca una época en ese ámbito. La noción de literatura popular se ve progresivamente sustituida por la de literatura "de gran difusión". La literatura popular pierde su autonomía y se integra a la historia del libro y de la lectura, a la historia de los editores y de las redes de difusión. Acerca de los textos en sí, existe un mayor interés por su recepción y las diferentes formas de su apropiación por parte de lectores, cuya competencia frente al texto impreso puede variar desde la necesidad de recurrir a un mediador por la vía de la canción o la lectura en común hasta la capacidad de descifrar lentamente un texto, en voz baja, o de leerlo en silencio.

Hoy, ¿qué balance puede hacerse en torno a la noción de "lo popular" y sobre la evolución de las perspectivas desde los años ochenta? La cultura popular "tradicional" ya no entusiasma ni a los etnólogos y ni a las instituciones. En cambio, existe un creciente interés por las culturas regionales y las culturas étnicas. En Francia, los sociólogos han desarrollado estudios sobre la gran burguesía o la aristocracia, y las encuestas sobre las culturas obrera o campesina contemporáneas son mucho menos numerosas que en los años setenta. Pero, desde hace una década, existen nuevos estudios que abordan la cultu- ra urbana y la de los suburbios especialmente desde el punto de vista de los lenguajes en uso, del fenómeno de los grupos de edad y de las bandas, del mestizaje cultural y más ampliamente, de la cuestión de la exclusión social. La Misère du monde, ${ }^{23}$ que reunió en 1993, bajo la dirección de Pierre Bourdieu, diversos trabajos de campo en forma de encuestas, evoca con precisión esos problemas. En ese mismo momento se manifiesta en los títulos de las obras una evolución léxicográfica significativa, a la vez divertida y un poco irritante, que muestra que la noción de "lo popular" resultaba incómoda, casi tabú: en lugar de las clases y de las prácticas populares, se habla de "gente humilde", de "cosas banales", de "artes modestas". En Escrituras ordinarias (La escritura común), libro dirigido por Daniel Fabre en 1993, se habla también de modos de escritura "comunes" y no populares, sustitución interesante por otra parte, ya que abre nuevas pistas de reflexión al poner en escena la escritura que permaneció manuscrita, la de los diarios íntimos, los cuadernos de recetas, los intercambios epistolares, etc. Michel de Certeau dedica, en 1980, su libro L'Invention du quotidien ${ }^{24}$ "al hombre ordinario" y Pierre Sansot, en Les Gens de puz (La gente de poco), obra publicada en 1994, evoca las prácticas ordinarias que "tienen a su favor la continuidad, este fondo de vida perpetua sin el que nuestra existencia se interrumpiría". Escoge estudiarlas porque, dice, los otros sistemas de pensamiento, el arte, la historia, la política, la religión han perdido toda capacidad de seducción.

${ }^{23}$ Existe una edición en español, Bourdieu, Miseria, 1.999. [N. del E.]

${ }^{24}$ Existe una edición en español, Certeau, Imención, 1996. 


\section{SECUENCIA}

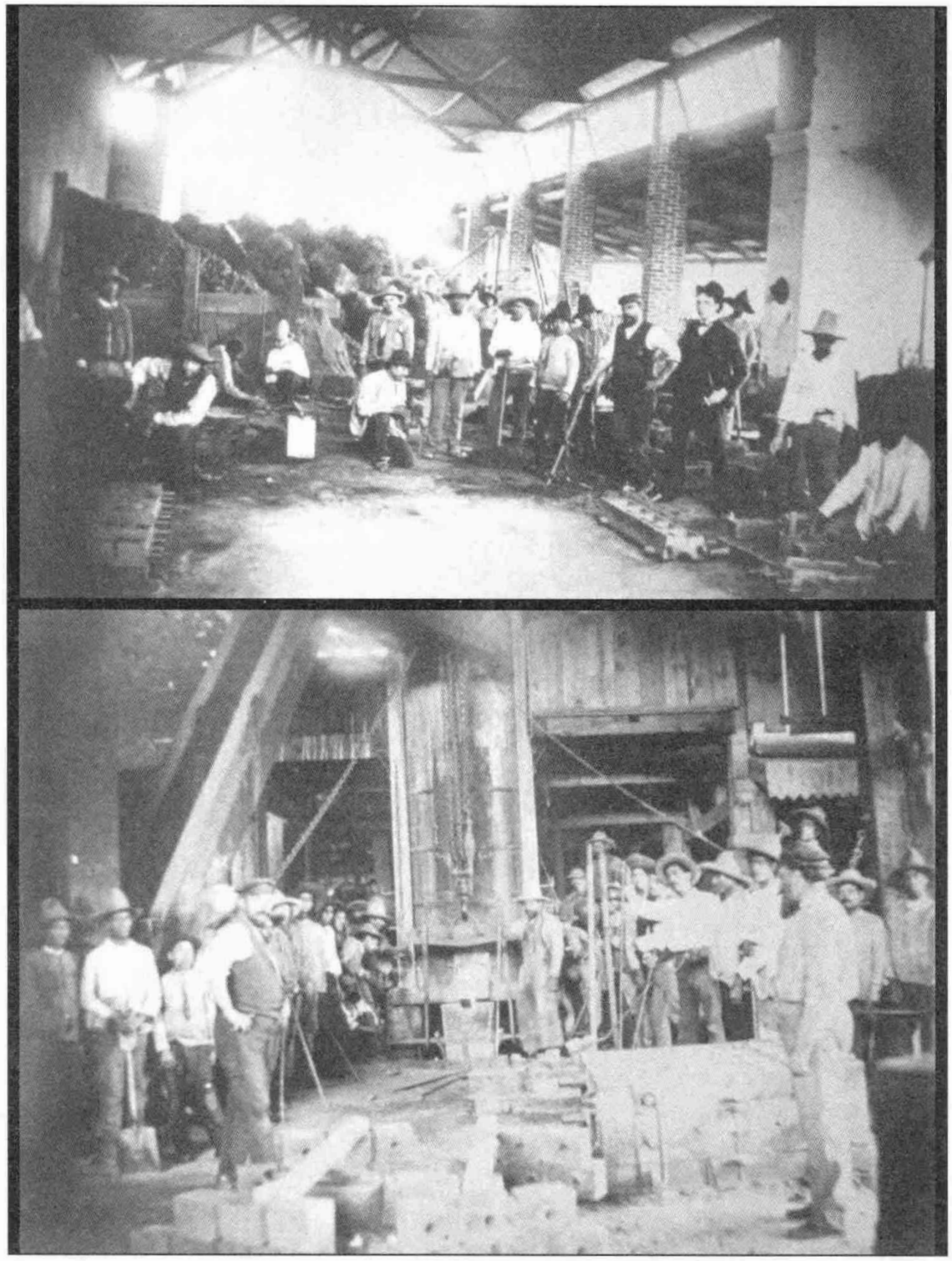




\section{SECUENCIA}
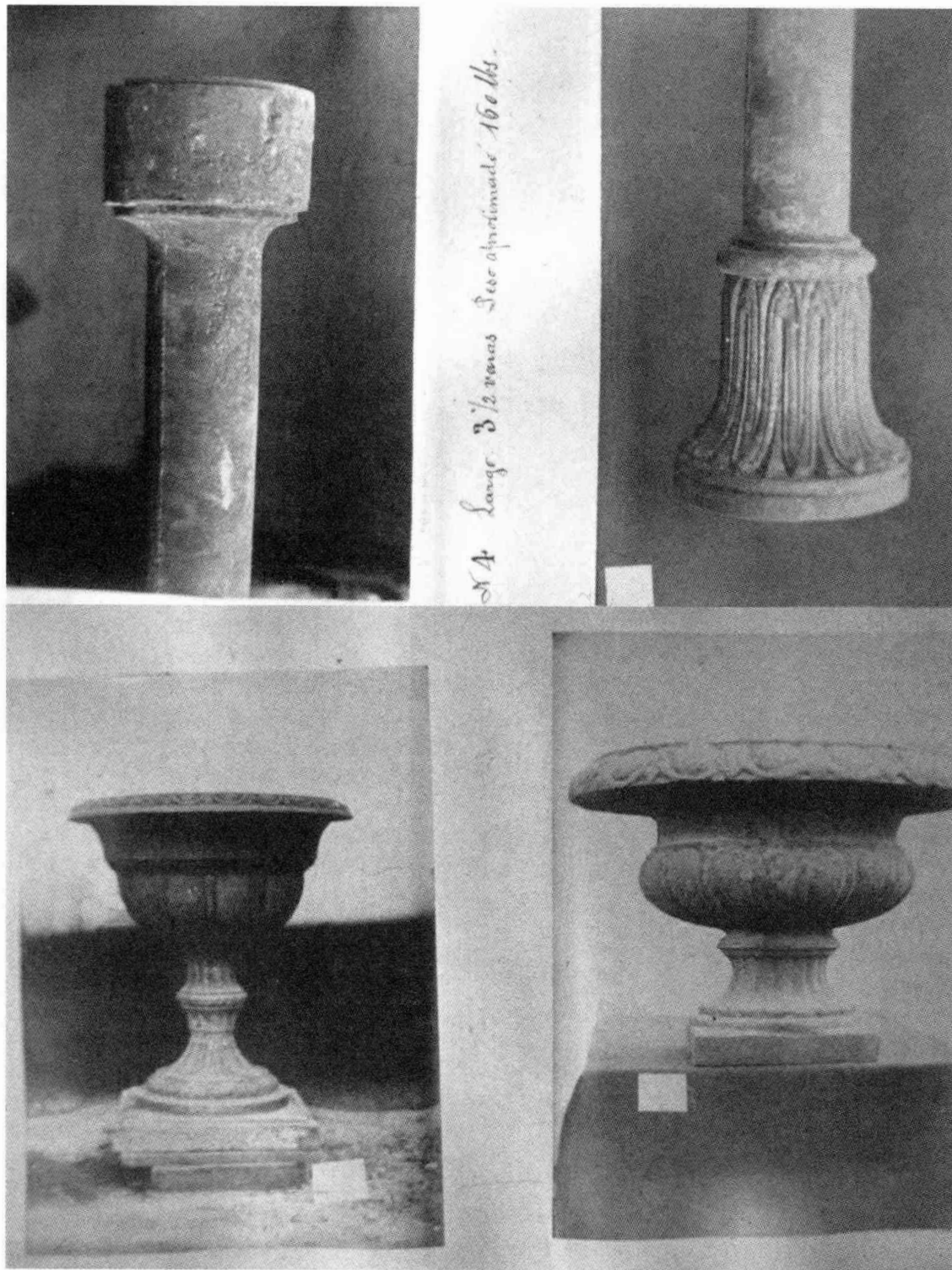


\section{SECUENCIA}
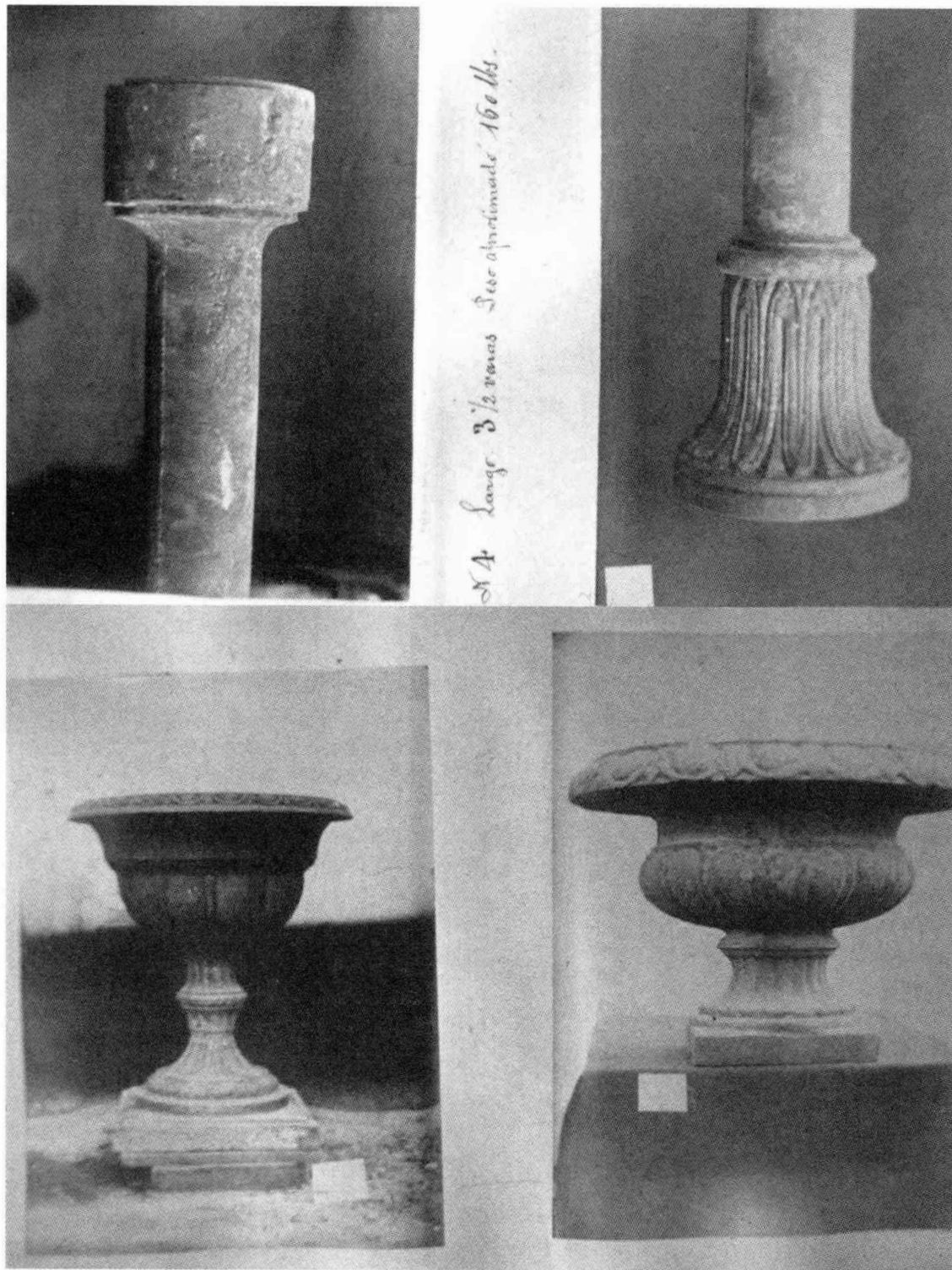
Hemos entrado, por lo tanto, en un periodo de desencanto marcado por el fin de las grandes utopías sociales. En esta perspectiva, la noción de cultura popular ya no tiene verdadera razón de ser. Pierde su contenido político y se neutraliza en el desmenuzamiento cotidiano de la banalidad. Con base en una suerte de vuelco epistemológico, los historiadores de nuestra década ya no toman como punto de partida las clases sociales, sino los modos de vida, las modos de distraerse, de alimentarse, de vestirse. Así, Georges Pérec proponía como consigna: "Haga el inventario de sus bolsillos. Interrogue sus cucharitas." Los historiadores se dedican a una antropología de lo cotidiano y rastrean en los archivos fragmentos de palabras y de gestos, siguen el desplazamiento de los rumores de la plaza pública, publican relatos de vida y memorias, como las de Jamerey-Duval, pastor del siglo XVIII que se volvió bibliotecario del duque de Lorraine o las de Ménétra, artesano vidriero y compañero de la vuelta a Francia. Los trabajos de Arlette Farge, La Vie Fragile, ${ }^{25}$ en 1986, y Dire et mal dire, en 1992, analizan a partir de los archivos policiacos la vida del pueblo parisino día con día, mientras que la "microhistoria" a la italiana de Giovanni Levi en L'Eredità immateriale: carriera d'un esorcita nel Piamonte nel Seicento ${ }^{26}$ privilegia a un destino singular (y ya no colectivo) que permite iluminar, a la escala de un pueblo, el funcionamiento más general de la sociedad.

Hoy en día las apuestas ideológicas se han disipado. Podemos ahora tomar dis-

${ }^{25}$ Existe edición en español, Farge, Vida, 1994 [N. del E.]

${ }^{26}$ Existe edición en español, Levi, Herencia, 1990. [N. del E.] tancia respecto a la idealización romántica del pueblo que el siglo XIX nos había transmitido, y respecto a una concepción de la literatura popular que la transformaba en el conservatorio del alma nacional. Debemos también desarrollar más las perspectivas comparativistas. Ése fue el objetivo de dos coloquios recientes, uno organizado por Roger Chartier y H. J. Lüsebrink sobre Colportage et lecture populaire. Imprimés de large circulation en Europe $X V I^{e}-X I X^{e}$ siècles $^{27}$ (Venta ambulante de libros $y$ lectura popular. Impresos de gran circulación en Europa, siglos XVI a XIX) y otro dirigido por H. J. Lüsebrink, Y. G. Mix, J. Y. Mollier y P. Sorel sobre Les Lectures du peuple en Europe et dans les Amériques XVII ${ }^{e}-\mathrm{XX}^{e}$ siècles $^{28}$ (Las lecturas populares en Europa y en América, siglos XVII-XIX). Finalmente, hay que manejar con prudencia la oposición, en ocasiones simplista, entre cultura popular y cultura erudita. A mi modo de ver, y con tal de redefinirla, la noción de literatura popular no está rebasada. Tiene que tomar en cuenta a la vez lo vivido, lo cotidiano y lo popular sin considerar que la banalidad de las existencias individuales deba necesariamente predominar sobre las conductas colectivas. La utilización más serena del término "lo popular" permitiría volver a otorgar una definición genérica a las obras literarias -pensemos por ejemplo en las "novelas populares" del XIX-y ampliar el alcance sociológico de su difusión, explicando de manera más satisfactoria los modos de funcionamiento de las primeras literaturas de vulgarización antes de la era de los medios masivos de comunicación. El redescubrimiento de la cultura popular en la década de 1960

\footnotetext{
${ }^{27}$ Chartier y Lüsebrink, Colportage, 1996.

${ }^{28}$ Lüsebrink et al., Lectures, 2003.
} 
revolucionó la historia social y cultural y permitió descubrir toda una cara de nuestra literatura que había sido olvidada. Nos toca continuar interrogando los fines que ésta perseguía.

\section{BIBLIOGRAFÍA}

-Aarner, A. y S. Thompson, The Types of the Folktale. A Classification and Bibliography, Academia Scientiarum Fennica, Helsinki, 1961, 2 vols.

-Bakhtine, Mikaël, L'ceuture de François Rabelais et la culture populaire au Moyen Age et sous la Renaissance, Gallimard, París, 1970.

-Baroja, C., "Ensayo sobre de la literatura de cordel", Revista de Occidente, 1969, Madrid.

-Botrel, J. F., "Los ciegos vendedores ambulantes de impresos en España", Mélanges de la Casa de Velázquez, núm. XX, 1974, Madrid.

-Bourdieu, Pierre, La miseria del mundo, FCE, Madrid, 1999.

-Burke, Peter, Popular Culture in Early Modern Europe, Londres, 1978.

-Capp, B., English Almanacbs 1500-1800. Astrology and Popular Press, Cornell University Press, Ithaca-Nueva York, 1979.

-Certeau, Michel de, La invención de lo cotidiano, Alejandro Pescador (trad.), Universidad Iberoamericana/Instituto Tecnológico y de Estudios Superiores de Occidente/Centro Francés de Estudios Mexicanos y Centroamericanos, México, 1996, 2 vols.

-Chartier, Roger, Laturas y lectores en la Francia del antiguo régimen, Instituto Mora, México, 1994.

-Chartier, Roger y H. J. Lüsebrink, Colportage et lecture populaire. Imprimés de large circulation en Europe XVIe-XIXe siècles, IMEC Éditions, París, 1996.

-Eisenstein, Elizabeth L., The Printing Press as an Agent of Change. Communications and $C u l-$ tural Transformations in Early Modern Europe, Cambridge University Press, Cambridge, 1979.
-Engelsing, Rolf, Zur Sozialgeschichte deutscher Mittel- und Unterschichten, Gotinga, 1973.

-Farge, Arlette, La vida frágil, Instituto Mora, México, 1994 (Itinerarios).

-Foucault, Michel, Vigilar y castigar, Siglo XXI Editores, México, 1984.

-Ginzburg, Carlo, Il formaggio e i wermi. Il cosmo di un mugnaio del'500, Einaudi, Turín, 1976.

- El queso y los gusanos, Francisco Martín (trad.), Muchnik Editores, Barcelona, 1997.

-Gramsci, Antonio, Los intelectuales y la organización de la cultura, Juan Pablos, México, 1975.

-Hobsbawn, Eric, Bandits, Weidefeld \& Nicolson, Londres, 1969. , Primitive Rebels: Studies in Archaic forms of Social Movement in the 19 $9^{\text {th }}$ and $20^{\text {th }} \mathrm{Cen}$ turies, Manchester University Press, Manchester, 1974.

-Hoggart, Richard, The Uses of Literacy, Aspects of Working-Class Life, with Special References to Publications and Entertainments, Chatto \& Windus, Londres, 1957.

-Le Roy Ladurie, Emmanuel, El Carnaval de Romans: de la Candelaria al Miéroles de Ceniza, 1579-1580, Ana García Bergua (trad.), Instituto Mora, México, 1994 (Itinerarios).

-Levi, Giovanni, La herencia inmaterial, NEREA, Madrid, 1990.

-Luisebrink, H. J. et al., Les Lectures du peuple en Europe et dans les Amériques $\mathrm{XVII}{ }^{t}-\mathrm{X} \mathrm{X}^{e}$ siècles, Éditions Complexe, París, 2003.

-Mandrou, R., De la culture populaire aux XVII et XVII' siècles: la Bibliathèque blene de Troyes, Stock, París, 1964.

-Porchnev, Boris, Les soulèvements populaires en France de 1623 à 1648, SEVPEN, París, 1963.

-Propp, Vladimir, Morpbologie du conte, Seuil, París, 1965.

-Ramada Curto, Diego, "Literaturas de amplia circulación en Portugal" en R. Chartier y H. J. Lüsebrink (eds.), Colportage et lecture populaire. Imprimés de large circulation en Europe XVIeXIXe siècles, IMEC Éditions, París, 1996. 


\section{SECUENCIA}

-Rodríguez Monino, A., Diccionario de pliegos sueltos poéticos, Castalia, Madrid, 1970.

-Rudé, George, The Crowd in History, a Study of Popular Disturbances in France and England 1730-1848, J. Wiley and sons, Nueva YorkLondres, 1964.

-Schenda, Rudolf, Volk obne Buch. Studien zur Sozialgeschichte der populären Lesestoffe 17701910 , V. Klostermanncop, Frankfurt, 1970.

-Spufford, Margaret, Small Books and Pleasant Histories. Popular Fiction and its Readership in $17^{\text {th }}$ Century England, Cambridge University Press, Cambridge, 1981.

-Thompson, E. P., The Making of the English Working Class, Vintage Books, Nueva York, 1963.

-Thompson, Stith, Motif-Index of Folk-Literature, a Classification of Narrative Elements in Folk-Tales, Ballads, Myths, Fables, Mediaeval Romances, Exempla, Fabliaux, Jest-Books and Local Legends, Indiana University, Bloomington, $1932-1936,6$ vols. 